\title{
Treatment of the Budd-Chiari syndrome in polycythemia vera by repeated percutaneous transluminal angioplasty of a hepatic vein stenosis
}

\author{
M. NISHIKAWA \\ M.D. \\ S. MIYOSHI \\ Y. IMAI \\ M.D. \\ K. SEKI \\ M.D. \\ Y. MINAMI \\ M.D. \\ S. TARUI \\ M.D. \\ S. KAWATA \\ M.D. \\ H. NAKAMURA* \\ M.D.
}

The Second Department of Internal Medicine, and *Department of Radiology, Osaka University Medical School, Osaka, Japan

\section{Summary}

This report is of a 63-year-old man with polycythemia vera who developed the Budd-Chiari syndrome due to right hepatic vein stenosis. Diagnosis was made by laparoscopy and liver biopsy, and confirmed by hepatic venography. The patient was treated by percutaneous transluminal angioplasty, and recovered completely from ascites, leg oedema and venous stasis. No pulmonary embolism was observed. One month after angioplasty, a second laparoscopy and liver biopsy showed a marked improvement in hepatic congestion and haemorrhagic necrosis, thereby confirming the effectiveness of this technique in treating the Budd-Chiari syndrome. Further treatments with percutaneous transluminal angioplasty were required with a good clinical outcome.

\section{Introduction}

Occlusion of the hepatic veins, or the Budd-Chiari syndrome, is a rare condition which is fatal in most cases. Characteristic symptoms are abdominal pain, enlarged liver, ascites and leg oedema. These are due to congestion of the liver and portal hypertension. Therapeutic measures are therefore directed towards relieving the congestion and lowering the portal hypertension. This paper reports a case of the BuddChiari syndrome in which successful treatment was

\footnotetext{
Correspondence: Masahiro Nishikawa, M.D. The Second Department of Internal Medicine, Osaka University Medical School, Fukushima, Fukushima-ku, Osaka, Japan, 553
}

achieved by repeated percutaneous transluminal angioplasty (PTA) of the stenosed hepatic vein.

\section{Case report}

A 63-year-old man was admitted in August 1980, because of leg oedema. He had been in good health until April 1980, when he noted a weight-gain of approximately $5 \mathrm{~kg}$. A doctor noticed an enlarged liver, ascites, leg oedema and polycythaemia. The patient was transferred to our hospital for further examination.

Physical examination on admission revealed dilated abdominal veins in the epigastric region, an enlarged liver $4 \mathrm{~cm}$ below the right costal margin, the spleen $1.5 \mathrm{~cm}$ below the left, and bilateral leg oedema.

Laboratory investigations showed haemoglobin $19 \cdot 2 \mathrm{~g} / \mathrm{dl}$ haematocrit $0 \cdot 56$, white cell count, platelets and erythrocyte sedimentation rate normal. Total red cell volume $57 \cdot 7 \mathrm{ml} / \mathrm{kg}$ (normal 26-33), leucocyte alkaline phosphatase score 432 (normal 15-100), glutamic oxaloacetatic transaminase (GOT) 20 u./ litre (normal 0-25), alkaline phosphatase $1110 \mathrm{u} . /$ litre (normal 33-164), bilirubin $2 \mathrm{mg} / \mathrm{dl}$, albumin 36 $\mathrm{g} /$ litre, plasma ammonia $\left(\mathrm{NH}_{3}\right) 1500 \mu \mathrm{g} /$ litre (normal $180-480)$, indocyanine green retention rate $(0 \cdot 5$ $\mathrm{mg} / \mathrm{kg}$ ) at $15 \mathrm{~min}\left(\mathrm{ICG}_{\mathrm{R}^{15}}\right) 29 \%$ (normal 0-10), prothrombin time $67 \%$, fibrin degradation products normal. Serum creatinine, urinalysis, blood electrolytes, serological tests, and chest X-ray were all 


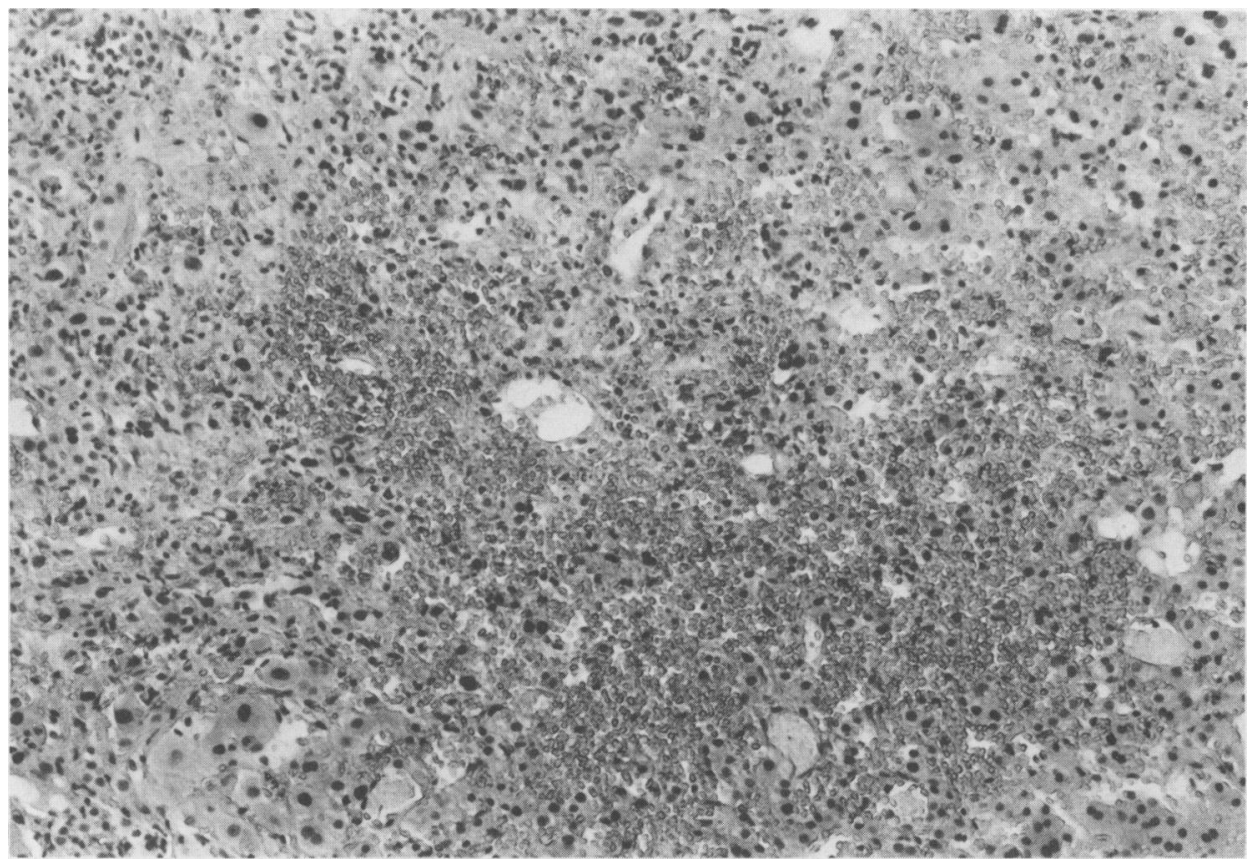

FIG. 1. Liver biopsy, showing intense congestion and centrilobular haemorrhagic necrosis. The sinusoids are dilated. (HE, $\times 100)$

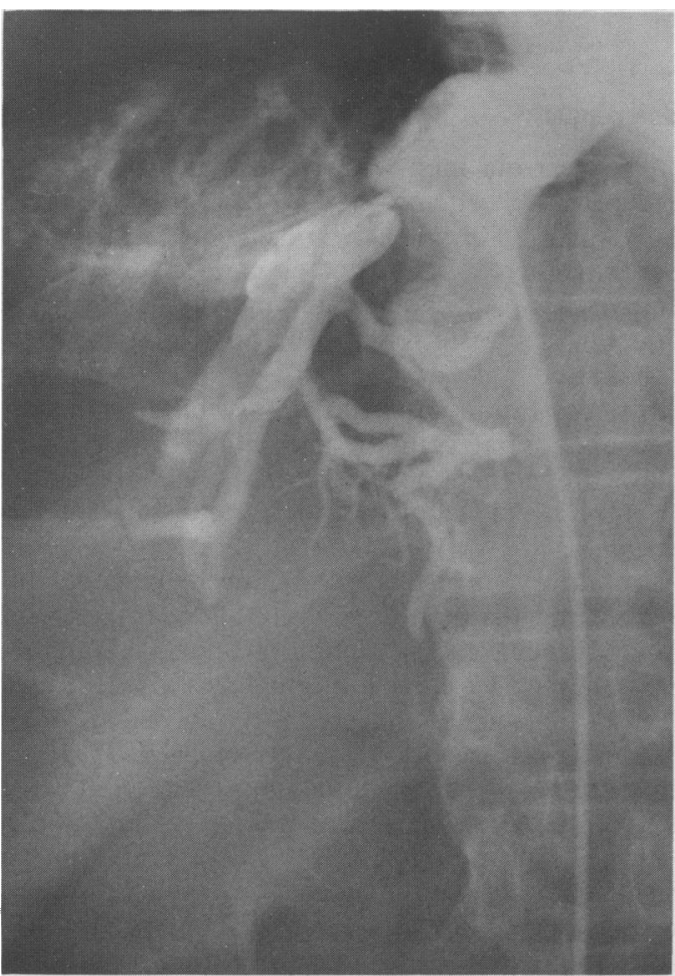

FIG. 2. Hepatic venogram, showing the dilated right hepatic vein. The catheter passed through a stenosed segment. normal. Electrocardiogram showed an old anterose tal myocardial infarction. Computed tomograph ${ }^{n}$ (CT) liver scan showed a hypertrophic caudate lobo, 응 but liver scintiscan showed no central uptake. $\overrightarrow{\mathrm{At}}$ laparoscopy, congestion in the right lobe of the liver was noticed, and histology of the liver biopsy $\%$ specimen showed centrilobular haemorrhagic necro- $\propto$ sis (Fig. 1). Hepatic venogram revealed stenosis of the $\vec{\overrightarrow{ }}$ right hepatic vein near the inferior vena cava (IVC) 3 (Fig. 2). IVC-gram showed no obstruction of the IVC $\supset$ except for a narrowing of the hepatic segment due to an enlarged caudate lobe.

Figure 3 illustrates the course of the patient's illness. Percutaneous transluminal angioplasty (PTA) as described by Gruntzig (1978) was performed using a balloon of diameter $6 \mathrm{~mm}$. Leg oedema and $ᄋ$ dilatation of the abdominal veins disappeared after a $₹$ few days of diuresis, and the liver diminished in size from $4 \mathrm{~cm}$ to $1.5 \mathrm{~cm}$ below the right costal margin. $D$ Plasma ammonia fell to the normal range. Alkaline phosphatase also fell to $550 \mathrm{u}$./litre. $\mathrm{ICG}_{\mathrm{R}^{15}}$ improved $\overline{\mathrm{N}}$ to $12 \%$. One month later, a second laparoscopy and ${ }^{\circ}$ liver biopsy was performed. Neither hepatic conges- $\mathcal{N}$ tion nor haemorrhagic necrosis was observed (Fig. 4). స్ట However, $2 \frac{1}{2}$ months after PTA, the patient again 0 developed hepatomegaly and leg oedema. Plasma 0 ammonia, alkaline phosphatase and $I_{C G_{R} / 5}$ again $\mathbb{D}$ rose. A second PTA was performed 3 months later, $\stackrel{\infty}{+}$ followed by venesections, but the effect was $\square$ evanescent. One month later, a third PTA 


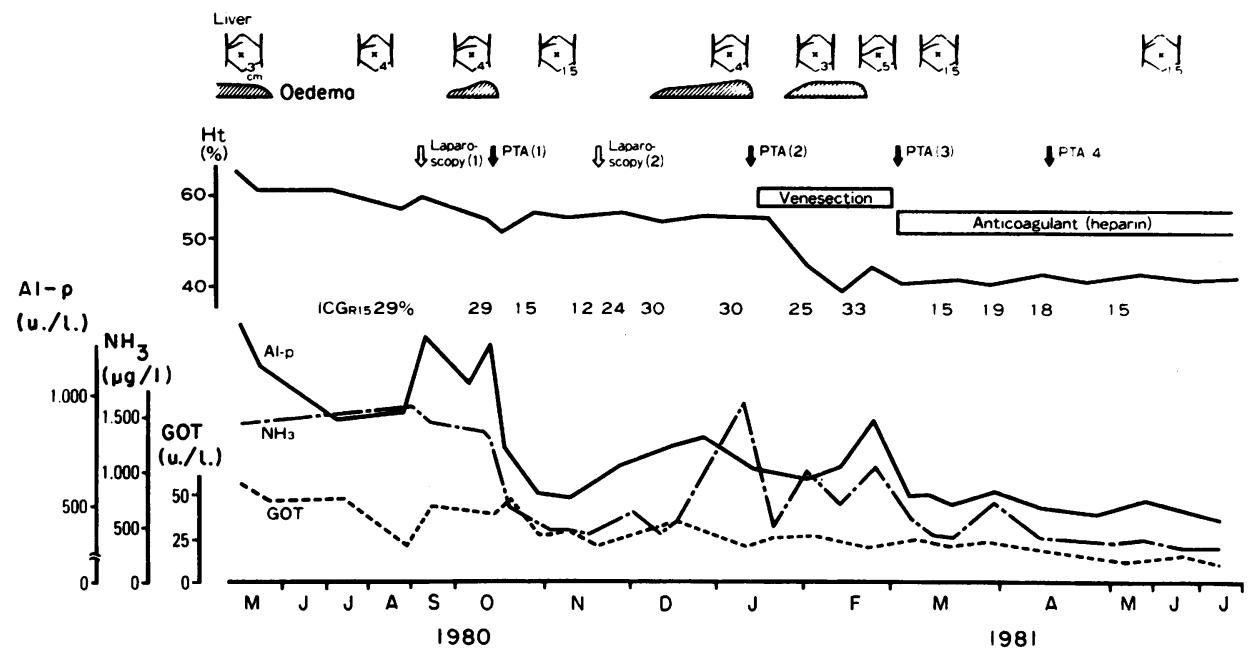

FIG. 3. Clinical course. Ht, haematocrit; PTA, percutaneous transluminal angioplasty; AL-P, alkaline phosphatase; GOT, glutamic oxalacetic transaminase; $I_{C G} 1$, indocyanine green retention time at $15 \mathrm{~min}$.

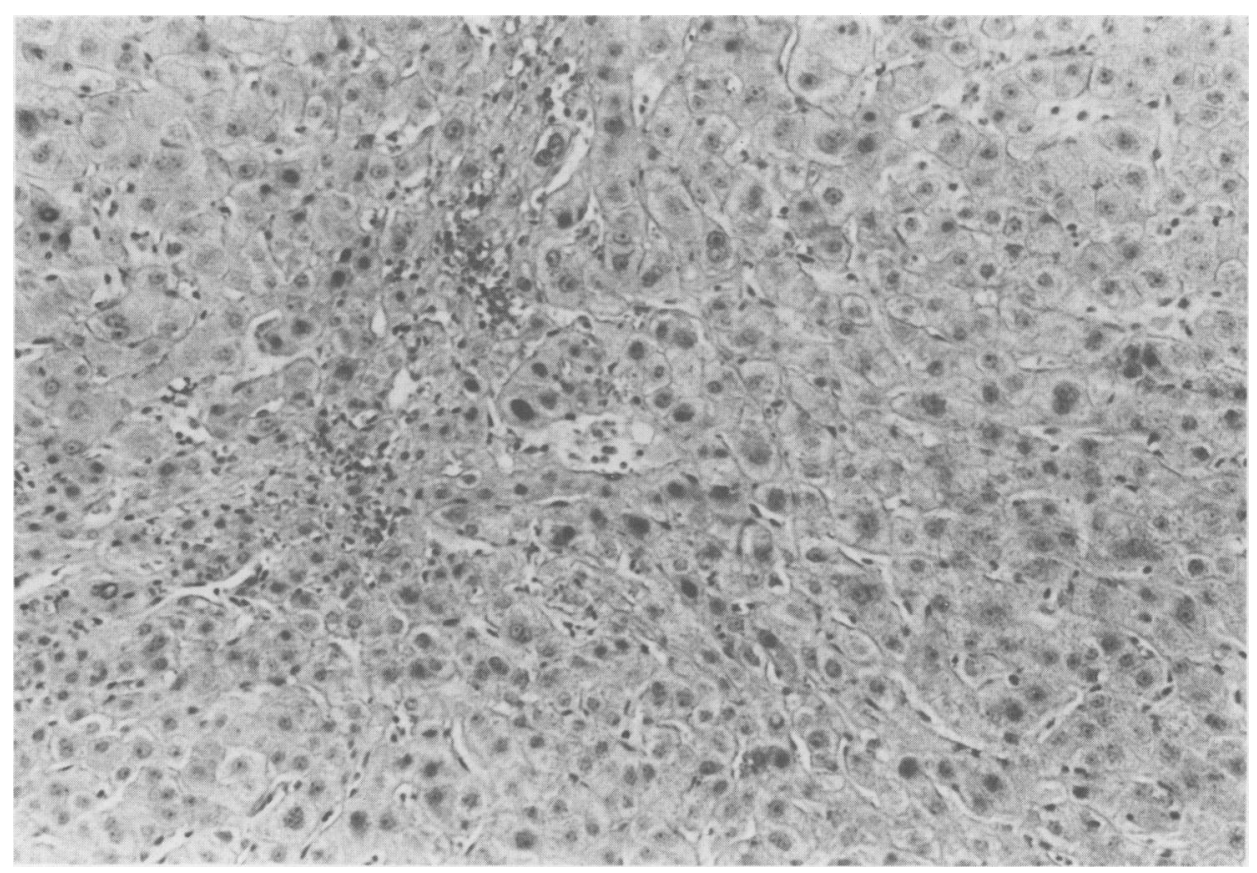

FIG. 4. Liver biopsy one month after the first PTA. Parenchyma in the central area has partially replaced fibrous tissues, but the haemorrhages have disappeared. (HE, $\times 100)$.

was performed with anticoagulant therapy (heparin $10 \mathrm{u} . / \mathrm{kg} / \mathrm{hr}$ ). A fourth PTA was performed using a larger balloon (diameter $8 \mathrm{~mm}$ ) after a further interval of one month. After which, the pressure gradient between the right hepatic vein and the IVC fell to $4 \cdot 1 \mathrm{cmH}_{2} \mathrm{O}$. The patient fully recovered, the plasma ammonia remains normal, the alkaline phos- phatase ranges from 500 to $600 \mathrm{u}$./litre, and $I_{C G_{R^{15}}}$ is $15 \% 4$ months after the final PTA.

\section{Discussion}

The Budd-Chiari syndrome, caused by hepatic vein thrombosis or IVC obstruction, is characterized 
by hepatosplenomegaly, ascites, leg oedema, mild jaundice and oesophageal varices due to congestion of the liver and portal hypertension. If decompression is not performed, the portal hypertension symptoms become more prominent and eventually the patient dies of gastrointestinal haemorrhage or of hepatic coma (Reynolds and Peters, 1975). The Budd-Chiari syndrome following membranous obstruction of the IVC can be successfully treated surgically using transcardiac membranotomy (Kimura et al., 1963; Takeuchi et al., 1971). Parker (1959), reviewing 149 reported cases plus 14 cases of his own, found polycythemia vera was the most common cause of hepatic vein thrombosis when portacaval shunt (Orloff and Johansen, 1978) and portopulmonary shunt (Akita and Sakoda, 1980) have been common choices for treatment. These procedures show favourable results in decreasing portal hypertension, but also have a high incidence of postoperative encephalopathy.

The efficacy of PTA by the technique described by Gruntzig (1978) has been attested to in various obstructive diseases (Gruntzig et al., 1978; Rankin et al., 1981). In this patient, congestion of the liver and portal hypertension markedly diminished after PTA. Efficacy was also confirmed by laparoscopy and liver biopsy. The patient, however, developed hepatomegaly, leg oedema and venous stasis again $2 \frac{1}{2}$ months after the first PTA, and required further PTA treatment. Although PTA was effective in the relief of the congestion, venesection after the second PTA was not effective in preventing a recurrence of the stenosis. Anticoagulant therapy (Langer et al., 1975) after the third PTA, on the other hand, had a beneficial effect not only in prevention of the recurrence but also in the relief of the congestion. This suggests that a state of hypercoagulability was present in the liver due to blood stasis, especially when FDP is in the normal range, as was the case in this patient.

PTA is relatively easy to perform, repeatable, and is more effective than normal operative procedures. This study also indicated the efficacy of applying anticoagulant therapy in conjunction with PTA in cases of the type described in this paper.

\section{References}

AKITA, H. \& SAKODA, K. (1980) Portopulmonary shunt by $\vec{A}$ splenopneumopexy as a surgical treatment of Budd-Chiari syn- $\omega$ drome. Surgery, 87, 85 .

GrUNTZIG, A. (1978) Transluminal dilatation of coronary-artery stenosis. Lancet, i, 263.

Gruntzig, A., KuhlmanN, U., Vetter, W., Lutolf, U., Meier, i B. \& SiEgENTHALER, W. (1978) Treatment of renovascular $\infty$ hypertension with percutaneus transluminal dilatation of a renal artery stenosis. Lancet, i, 264.

Kimura, T., Shirotani, H., Tsunekawa, K., Hayashi, K., c Matsuda, S., Hirooka, H., Terada, M., Iwahashi, K., $\rightarrow$ MAETANI, S. \& IKADA, H. (1963) Membranous obliteration of inferior vena cava in the hepatic part. Nihonrinsho, 21, 125.

LANGer, B., Stone, R.M., Colapinto, R.F., MeindoK, H., Philips, M.J. \& FiSHER, M.M. (1975) Clinical spectrum of the Budd-Chiari syndrome and its surgical management. American Journal of Surgery, 129, 137.

ORLOFF, M.J. \& JoHANSEN, K.H. (1978) Treatment of Budd-Chiari syndrome by side-to-side portacaval shunt: Experimental an $\overrightarrow{0}$ clinical results. Annals of Surgery, 188, 494.

PARKER, R.G.F. (1959) Occlusion of the hepatic vein in marr. Medicine, 38, 369.

Rankin, R.N., Keowen, P.A., Ulan, R.A. \& Stiller, C.R. (1981) Percutaneus transluminal dilatation of transplant renal artery stenosis. Postgraduate Medical Journal, 57, 300.

REYNOLDS, T.B., \& PETERS, R.L. (1975) Budd-Chiari syndrome. (Ed by Schiff, L.), 4th edn, p. 1402. J. B. Lippincott, Philadelphia.

TAKeUCHI, J., TAKadA, A., Hasumura, Y., MatsudA, Y. \& IKEGAMI, F. (1971) Budd-Chiari syndrome associated with obstruction of inferior vena cava. American Journal of Medicine, 51, 11. 